Plomp, M.G.A., Batenburg, R.S., Rooij, R.C.M. van. Determining chain digitisation maturity: a survey among Dutch CIOs. Electronic Markets: 2012, 22(4), 283-293

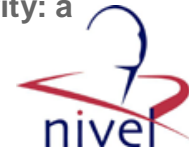

\begin{tabular}{|l|l|}
\hline $\begin{array}{l}\text { Postprint } \\
\text { Version }\end{array}$ & 1.0 \\
\hline Journal website & http://link.springer.com/content/pdf/10.1007\%2Fs12525-012-0102-6 \\
\hline Pubmed link & \\
\hline DOI & $10.1007 / s 12525-012-0102-6$ \\
\hline
\end{tabular}

This is a NIVEL certified Post Print, more info at http://www.nivel.eu

\title{
Determining chain digitisation maturity: a survey among Dutch CIOs.
}

\author{
MARIJN G. A. PlOMP \& RONALD S. BATENBURG \& RON C. M. VAN ROOIJ
}

\begin{abstract}
Interorganisational or chain information systems have become a frequent subject of scientific research, but not often an empirical perspective on these systems is taken. In this study we develop a model for measuring the chain digitisation maturity of organisations (as a proxy for chains) and validate it by conducting a survey among 33 CIOs. We measurematurity on both technology and organisation, on both the supply and demand side of the focal organisations, resulting in four maturity dimensions. Furthermore, we show through a cluster analysis that the dataset can indeed be differentiated along those dimensions. Finally, three determinants, namely complexity of chain digitisation solutions, synchronisation of data, and the size of the organisation, appear to be correlated with chain digitisation maturity. We conclude that the topic of chain digitisation alignment deserves further research, as does its situationality for profit and non-profit organisations.
\end{abstract}

\section{INTRODUCTION}

The term chain information systems (CIS) has been coined by Grijpink as a new term and a critical precondition for successful digital collaboration in (inter)organisational chains (cf. Grijpink 1999, 2010). CIS can be viewed as a specific subset of interorganisational (information) systems (IOIS or simply IOS), which are probably better known as these have a longer history (e.g. Barrett and Konsynski 1982). Many different terms belong to the IOS field. Most prominently are supply chain management (SCM) related terms such as supply chain automation, supply chain integration, and collaborative planning, forecasting, and replenishment (CPFR). Also IOS cover organisational/ business related terms such as interorganisational collaboration, virtual organisations, and value networks or IT-related terms such as interoperability, e-business, and chain computerisation.

In this paper, we focus on CIS and 'chain digitisation' instead of IOS, to stress that it encompasses collaboration between multiple organisations. We define chain digitisation as "firms working together along value/supply chains through ICT" (Plomp and Batenburg 2010). It is therefore to be interpreted as a multiparty concept. The interest in CIS is driven by trends like increasing industry network complexities, due to more competition, demanding consumers and suppliers, increasing governance, and cost control as a result of the recent economic recession. This rightly applies to the public domain, as the issues of public bodies (e.g. healthcare, justice) call for a multiparty and interorganisational approach. The alleged 
advantages of CIS appear to specifically meet these challenges of public organisations, and promise cost reduction, productivity improvements, and innovation (Morrel and Ezingeard 2002). Many papers address these advantages through studying (the maturity of) specific organisational information systems. However, there is not much research on the maturity of CIS on the chain level. Furthermore, we are aware of few empirical studies on this topic, especially those that focus on both the supply and the demand side.

Based on the above, we formulate the following research question for this paper: How can chain digitisation maturity be measured and how do organisational and technological characteristics determine an organisation's chain digitisation maturity? The meaning of the title of this paper is therefore twofold: (i) how to determine chain digitisation maturity and (ii) what factors determine chain digitisation maturity? The structure of the remainder of this paper is as follows. First, an outline of the theoretical background of this research will be given, followed by our conceptual model.

Next, the applied research methods will be presented, followed by a description of the results. This results section presents the scores on the variables studied, and also the outcome of both a cluster and a correlation analysis. These results lead to the conclusion, in which the key points of this research are summarised. We end with some topics of discussion, including limitations of this study and opportunities for future research.

\section{THEORY \& CONCEPTUAL MODEL}

While in IOS and SCM traditionally a distinction between the supply and demand side of chain management is made, from a chain digitisation perspective this distinction is not or less relevant. When the object of analysis is the entire chain, a distinction between supply and demand side cannot be made. In that case, the focus lies on the interorganisational collaboration as a whole, which takes place on the chain level (Grijpink 1999). However, when we focus on the chain digitisation capabilities of a specific organisation, a distinction between its supply and demand side maturities can and should be made (Frohlich and Westbrook 2001). For example, the maturity with regard to supply-side functions like (e-)procurement (Plomp and Batenburg 2009) is not necessarily related to the maturity of demandside functions like CRM (Batenburg and Versendaal 2007). When we are interested in maturity from a chain perspective, but use a specific organisation as the unit of analysis, there is a measurement possible on both the 'upstream' and 'downstream' side of the focal organisation. Hence, chain digitisation maturity is treated here as a two-sided concept.

In analysing this concept, we specifically focus on the relationship with the external environment, i.e. the organisation's suppliers and customers. In the tradition of the Resource Based View (RBV), which was described as "analysing firms from the resource side rather than from the product side" (Wernerfelt 1984), the focus lies more on the internal resources of an individual organisation. Barney (1991) further developed this theory by emphasising that the RBV focuses on the internal organisation and by defining resources as "all assets, capabilities, organizational processes, firm attributes, information, knowledge, etc. controlled by a firm”. In order for resources to be of (strategic) value to a firm, they need to adhere to the VRIN criterion: they should be valuable, rare, inimitable and non-substitutable. More 
Plomp, M.G.A., Batenburg, R.S., Rooij, R.C.M. van. Determining chain digitisation maturity: a survey among Dutch CIOs. Electronic Markets: 2012, 22(4), 283-293

recently, the related Dynamic Capabilities View (DCV) has been developed. DCV "offers the more dynamic variety of the RBV by emphasising that possessing a set of resources with VRIN characteristics is not enough to stay competitive in a changing business context" (Den Hertog 2010). Dynamic capabilities are defined as "the firm's ability to integrate, build and reconfigure internal and external competencies to address rapidly changing environments" (Teece et al. 1997). This shifts our attention to changing capabilities/resources, but also more towards the external environment: the value system. Or as Teece (2007) puts it: "the concept and practice of open innovation underscore the importance of broad-based external search and subsequent integration involving customers, suppliers, and complementors". In these external value chains or business networks, there are many important but hard to answer questions, e.g. related to opportunities and limitations, influence, and control (Håkansson and Ford 2002).

We depart here from the notion that the deployment of technology (i.e. IT) will be less useful and effective without considering the organisational dimension (e.g. Scott Morton 1991; Daft 2001; Turban et al. 2001; Luftman and Kempaiah 2007). This is particularly the case for the success of IOS (Zhu and Kraemer 2002) and hence we will research if and how this applies to CIS as well.We propose and apply a measurement model for chain digitisation, by designing maturity scales and levels of CIS, assuming that technology and management (or 'organisation') are constantly interrelated (e.g. Mumford 1987; Orlikowski 1992; Henderson and Venkatraman 1993).

For the dimensions and levels of our chain digitisation maturity model, we build upon our recent work on chain digitisation maturity (Plomp and Batenburg 2010). There, based on 22 existing maturity models a framework is defined, depicted in Fig. 1. It consists of two dimensions: technology and organisation, with four maturity levels each.

For the technological dimension, these levels are:

1. No chain automation. There is no interorganisational technology, i.e. there are no digital connections to the outside world.

2. E-business. ICT is used to cross the borders of the organisation. This is sometimes called extended ERP or XRP, indicating that the internal information system extends outside the organisation itself (Kalakota and Robinson 2001). In this phase, the focus lies on transactional processes.

3. E-collaboration. ICT serves collaboration between multiple parties in the chain. Standards and standardisation play an important role here. E-collaboration comprises tactical processes.

4. Open, $n$-tier sourcing. The ICT from the previous level is available and used by all ('n') parties within and between value chains. Data come from multiple locations through open standards and architectures (Van Beers and Bouwman 2007).

\section{[FIGURE 1]}

For the organisational dimension, the following levels have been defined: 1. No chain collaboration. There are no interorganisational relationships.

2. Bilateral collaboration. There is collaboration with another organisation, which is often a connected link of the value chain (e.g. a retailer working together with its supplier). 
3. Multilateral collaboration. The same as the previous level, but with multiple parties. It can for example be in the form of collaborative planning, forecasting, and replenishment (CPFR) or collaborative commerce (Turban et al. 2004).

4. Extended chain collaboration. There is collaboration between multiple parties across multiple links within and between value chains. The interaction is truly manyto-many and ' $n$-tier', including the customers and suppliers of all chain organisations.

As can be seen in Fig. 1, when these two dimensions are combined, four types of chain digitisation can be distinguished:

- Basic chain digitisation. Within this type of interorganisational chain, both collaboration and the available technology are at a low level. There is bilateral collaboration at best and technology is used for transactions only. Regarding their maturity, both dimensions are in balance, however. This can for instance be the case in interorganisational chains that encompass relatively standard and frequent processes and transactions, such as in markets for fast-moving consumer goods.

- Technological proficiency. Despite the fact that the interorganisational collaboration is still low, the available technology within this type of interorganisational chain is of a more sophisticated level (i.e. no less than at the point of e-collaboration). The two dimensions are not in balance. This can be the case if an interorganisational chain has standard, frequent transactions that require relatively low levels of trust between the parties. These can be eauctions or e-marketplaces in industrial markets for raw materials and the logistics/ transport sector.

- Relational proficiency. As the opposite of technological proficiency, within this type of interorganisational chain there is advanced collaboration (i.e. multilateral collaboration or more), but the technology lags behind with regard to the chain digitisation maturity. Again, there is no balance between the two dimensions. This could occur in interorganisational chains that deal with non-standard transactions that involve a high amount of trust and hence personal contact, such as in one-of-a-kind industry or project-based sectors like the construction industry.

- Advanced chain digitisation. Within this type of interorganisational chain, the available collaboration and the existing technology are both at the same, developed level. Hence, both dimensions are in alignment with each other. Interorganisational chains that concern products or services that have complex specifications but are nevertheless ordered with high or predictable frequency are examples of this type. Examples are the mature e-commerce industries such as travel agencies and multi-media consumer markets.

Although these four situations are intuitive, it should be noted that they do not imply a sequential order of development.

Furthermore, the figure may seem to indicate that one type is 'better' than the other, but concluding this would be incorrect. It is clear that there is more chain digitisation in the upper right quadrant than in the lower left, but this does not mean that organisations that are positioned in the latter quadrant are less successful: they might not need to grow to a higher maturity level because of their specific circumstances ('situationality'). 
In this paper, we add to the original model the aforementioned distinction between the supply and demand side, and the operationalisation of the levels by means of items for a questionnaire. Distinguishing the maturities at the supply and demand side of an organisation gives a more detailed view of that organisation's collaboration capabilities. In a way it serves as a proxy for backward and forward chain digitisation maturity, i.e. the degree of collaboration with other parties upwards and downwards the chain. The quantification of the model allows for the application of statistical methods, like cluster analysis. Furthermore, we are interested in finding the determinants that influence this maturity.

For the selection of the organisational and technological determinants of chain digitisation maturity, we studied existing literature on the adoption of IOS. A rigorous IOS literature review, concerning research articles that were published in 11 different IS journals between 1990 and 2003, has been performed by Robey et al. (2008). We extend their analysis here, by looking at different determinants coming from other and more recent publications.

However, there are two important differences between their research and ours. First, Robey et al. primarily discuss studies describing IOS adoption. Although related, this is not exactly the same as our concept of maturity.

Furthermore, in our model we specifically consider two sides (i.e. supply and demand) of the focal organisation.

Bunker et al. (2008) state that communication and information sharing are enablers of a collaborative culture, and hence have a positive effect on the adoption of IOS. They also emphasise that trust is required to stimulate adoption.

Teo et al. (2009) add that firm size is positively and significantly associated with the adoption of e-procurement.

Larger organisations are considered more capable of adopting innovations, due to larger financial resources and scale advantages. Also, large organisations are more likely to have transactions that suit IOS, at least with some of their trading partners (Geri and Ahituv 2008). Munkvold (2005) found that challenges in adoption of ecollaboration increase with the level of autonomy in the adoption process.

Batenburg and Constantiou (2009) state that e-business adoption is influenced by factors such as the synchronisation of data with suppliers and customers (increasing the compatibility of the e-business solutions) and the complexity of the ebusiness solutions.

Based on the literature discussed above, we formulate the following six hypotheses: H1 The ability of an organisation to communicate and collaborate (in terms of not being hindered by legacy systems) is positively related to its chain digitisation maturity.

H2 The level of trust an organisation puts in its value chain partners is positively related to its chain digitisation maturity.

H3 An organisation's autonomy (in terms of not being hindered by dominant players in the value chain) is negatively related to its chain digitisation maturity.

H4 The complexity of an organisation's chain digitisation solutions (in terms of its 'lock-in' with other value chain partners) is negatively related to its chain digitisation maturity.

H5 The importance of synchronisation of data for an organisation is positively related to its chain digitisation maturity.

H6 The size of an organisation is positively related to its chain digitisation maturity. 
Plomp, M.G.A., Batenburg, R.S., Rooij, R.C.M. van. Determining chain digitisation maturity: a survey among Dutch CIOs. Electronic Markets: 2012, 22(4), 283-293

These hypotheses regarding the determinants of chain digitisation maturity can be summarised in a conceptual model (see Fig. 2). Some of those determinants are of a purely organisational (e.g. interorganisational trust) or technological nature (e.g. complexity of chain digitisation solutions), whereas others are more mixed (e.g. synchronisation of data). In line with e.g. Robey et al. (2008), many other determinants can be thought of, but in this study we consider these to be the main determinants.

\section{[FIGURE 2]}

As follows from the conceptual model in Fig. 2, the independent variables are expected to have an effect on the dependent variable: the level of chain digitisation maturity of an organisation. The chain digitisation maturity level of an organisation is characterised by a technological and an organisational dimension, combined with the organisation's chain position measured at its supply and demand side.

\section{Data \& methods}

We used a survey to collect data to test our hypotheses, which were analysed through a cluster and correlation analysis. An online questionnaire has been distributed among 38 Chief Information Officers (CIOs) of Dutch organisations from different industries through the professional and personal network of the authors. Thismethod can be typed as convenience (but controlled) random sampling (cf. Lunsford and Lunsford 1995). No requirements were applied in the selection process (e.g. with respect to sector), except that the organisations had to be 10 FTE or larger. The CIOs were personally asked to participate in the research and fill in the online questionnaire.

If they agreed to participate, the URL of the online questionnairewas sent to them. In the questionnaire, additional instructions and motivation for the CIOs was given. The respondents were free to choose when and where they would complete the questionnaire, as long as the results were submitted before a clearly stated deadline. Table 1 indicates how the independent variables of our conceptual model have been operationalised. The first five determinants have been measured through statements, preceded by the question 'please indicate how the following statements represent your organisation'. The answer options were formed by a 7-point Likert scale ranging from 'strongly agree' to 'strongly disagree'. The factor size was measured through an open question.We looked at the total headcount here, based on the idea that the number of users is of greater importance than the number of FTEs. The measure remains a proxy however, as other factors (e.g. degree of outsourcing, line of business) likely play a role as well.

Table 2 shows how the dependent variable (chain digitisation maturity) in our conceptual model has been operationalised.

In total 32 statements about both technological and organisational maturity on both the supply and demand side of the organisation have been used, 7 or 9 per dimension. We 'mirrored' these statements for the supply and demand side, e.g. "receiving einvoices" versus "sending e-invoices" and "document joint process descriptions with suppliers" versus "document joint process descriptions with customers".

The respondents were asked to express how each statement fits their organisation. Four different answer categories were provided, namely: 
- 'Yes, for (almost) all of our [suppliers/customers]',

- 'Yes, for some of our [suppliers/customers]',

- 'Yes, for only one of our [suppliers/customers]', and

- 'No'.

In addition, a 'Do not know/cannot say' option was provided.

In total, we received 33 completed surveys. After data collection, the dataset has been processed to create scales for both the independent and dependent variables. First, variables were constructed based on the questions from Table 1 to measure the independent variable: the determinants of chain digitisation. Some questions have been recoded (i.e. reversed), because they were stated in a 'negative way'.

The scales for the dependent variable were constructed from the questions from Table 2. A reliability analysis was performed for each dimension, which resulted in Cronbach's alpha scores of .84 (technology, supply side), .96 (organisation, supply side), .86 (technology, demand side) and .94 (organisation, demand side). Finally, when we take these four categories together, we obtain an alpha of .96.

These scores imply a good reliability and therefore these five scales can be used to measure the dependent variable chain digitisation maturity (Nunnally and Bernstein 1994).

\section{[TABLE 1 AND TABLE 2].}

\section{RESULTS.}

\section{Context variables.}

Before testing our hypotheses, we first present some descriptive statistics. In our sample, profit organisations are dominant: 25 (75.8\%) are profit organisations, while 8 (24.2\%) are non-profit (by self-classification). With respect to the sector, we learn from Table 3 below that our sample is diverse. The manufacturing/producing and professional services sectors are overrepresented, whereas only one governmental organisation has participated.

Although all surveyed organisations had to be active in the Netherlands, some of them were active in other geographical areas as well. As can be seen at the left side of Table 4, there is a relevant distribution over the different areas of operation, i.e. local, national, continental and global scale.

\section{[TABLE 3]}

Because of our method of convenience random sampling, it is also useful to check the age distribution of the organisations in our sample (right side of Table 4). On average, organisations are active since 53.4 years, with a relatively high standard deviation of 65.2 years. This means that the sample does not merely consist of very recent startups, nor just of age-old organisations, but of a relevant mixture instead.

\section{Dependent variables}

The main variables to be analysed in this study are summarised in Table 5. The dependent variables (the different dimensions of chain digitisation maturity) all range between 1 and 4 . The average score on the 'technology, supply side' maturity appears to be the lowest (1.89; $\mathrm{SD}=0.72$ ), whereas the 'organisation, demand side' 
maturity is the highest (2.33; $\mathrm{SD}=1.07)$. The overall chain digitisation maturity score has a mean of $2.07(\mathrm{SD}=0.79)$. Only one organisation reached the maximum level of 4.00 for overall chain digitisation maturity, while 18 companies were positioned in the ' $\geq 1.00$; $<2.00$ ' range.

\section{Cluster analysis}

In order to find out whether our cases can indeed be differentiated along the dimensions of the model, and to get a better understanding of our dataset, we performed a cluster analysis on our dependent variables. We clustered the organisations in our sample twice: once for the supply side variables and once for the demand side variables. All variables were standardised prior to the cluster analysis procedure, in order to rule out spurious effects due to unequal variances (Kachigan 1991).

\section{[TABLE 4 AND TABLE 5]}

First, we performed a two-step cluster analysis for the organisation and technology variables on the supply side.

We used the log-likelihood distance measure and let the number of clusters be determined automatically. This leads to two clusters: one consisting of 17 cases (technology mean=1.47; organisation mean=1.21) and one consisting of 16 cases (technology mean=2.32; organisation mean=3.03). Applying Akaike's or Schwarz's Bayesian information criterion results in exactly the same clusters.

As with most (statistical) methods, the most prudent course is to use two different techniques to arrive at the clustering results (Kachigan 1991). Therefore, we performed an additional clustering using the k-means clustering method. When fixed on two clusters, this results in a cluster with 18 members and one with 15 members. These numbers differ by only one compared to our first clustering, and indeed one case has 'switched' to the other cluster. The mean technology and organisation scores of the clusterings are therefore also very similar. The two classifications are also highly correlated with each other: both Kendall's tau-b and Spearman's rho are .94 and significant $(p<.01)$. This entails that the two different clustering methods lead to very similar results, which makes the clustering more robust.

In Fig. 3 the clusters are visualised. The 33 cases have been plotted on the chain digitisation maturity model; one dot is bigger as it represents 3 cases with exactly the same scores. The grey areas indicate the two clusters. They overlap for the one case that is part of each cluster, depending on the method that is used. If we look at the two clusters, we see that one clearly represents the organisations that score low on chain digitisation maturity (i.e. all cases fall in the 'basic chain digitisation' quadrant). The other cluster mainly holds cases with medium or high levels of chain digitisation maturity.

Comparing the clusters on background variables, through chi-square tests for both sector and area of operation, and a $t$-test for age of the organisation, reveals no significant differences $(p>.10)$. For these analyses, the case that is part of both clusters was left out.

\section{[FIGURE 3 AND FIGURE 4].}

We performed a similar two-step cluster analysis for the organisation and technology variables on the demand side, which results into two clusters as well: one of 19 cases 
(technology mean=1.46; organisation mean=1.62) and one of 14 cases (technology mean=2.83; organisation mean=3.31). Applying Akaike’s or Schwarz’s Bayesian information criterion did not lead to different results.

Analogous to our supply side cluster analysis, we conducted a $k$-means clustering here as well. Fixed on two clusters, this leads to one cluster with 20 members and another cluster with 14 members. Once again, these numbers differ by only one compared to the first clustering, caused by one 'switching' case. The mean technology and organisation scores of the two clusterings are also very similar, resulting in the two classifications being highly correlated: Kendall's tau-b and Spearman's rho are again .94 and significant $(p<.01)$. This supports the soundness of the demand side clusters.

Figure 4 presents the results of the clustering procedure.

Note that some dots are bigger than others, representing two or three organisations that scored exactly the same. If we examine the clusters, we see that also for the demand side, one cluster mainly represents low scores, while the other contains mostly high scoring organisations with regard to chain digitisation maturity. No significant differences ( $p>.10)$ were found when comparing the clusters on background variables sector and area of operation (both chi-square tests), and age of the organisation (t-test). Once again, the case that is a member of both clusters was left out of these analyses.

Based on these analyses, we conclude that the cases in our dataset can be successfully clustered based on their chain digitisation maturity, for both the supply and demand side. In both cases two clusters emerge: one with mainly low maturity scores and one with mainly medium/high scores.

\section{Independent variables.}

The main statistics of the independent variables are listed in Table 6. Most of the independent variables range between 1 and 7, except 'communication and collaboration' and 'interorganisational trust', as no organisation scored a 1 on these variables. No organisation scored 7 on the variable 'interorganisational trust' either. The variable 'synchronisation of data' has a relatively high standard deviation of 2.28 , indicating that this is of great importance for some organisations, whereas it is not for others. As the employee size of an organisation is an in principle unbounded variable, its distribution is skewed and standard deviation relatively large (mean=12,300; $\mathrm{SD}=25,900$ ). Therefore we transformed this variable by taking its logarithm. The characteristics of the log-transformed variable are presented in Table 6.

\section{[TABLE 6].}

Correlation analysis Next, the relationships between the dependent and independent variables have been assessed using Pearson bivariate correlation analysis. The results are displayed in Table 7 . We employed one-tailed testing in accordance with the expected direction of the relations shown in Fig. 2.

From this table we learn that the first two variables 'communication and collaboration' and 'interorganisational trust' are not clearly related to the chain digitisation maturity level of an organisation. Both the four maturity dimensions and the overall maturity construct are not significantly correlated with either of these two independent variables. 
The variable 'autonomy' is significantly and negatively related to chain digitisation maturity $(p<.05)$, but only for the organisational dimension (i.e. both for the supply and demand side). This makes sense, as the content of this variable is related to this particular dimension (refer to Table 1). As the overall score contains both the technological and the organisational dimension, there is only a trend correlation $(p<.10)$ visible.

The 'complexity of chain digitisation solutions' variable is significantly and negatively related to chain digitisation maturity as well $(p<.05)$, but here only on the technological dimension (also for both the supply and demand side). Once again this is understandable, as its measurement includes technical aspects like being 'locked in'. In this case, however, the determinant is also significantly correlated $(p<.05)$ with the overall chain digitisation maturity variable.

The determinant 'synchronisation of data' is significantly and positively related to chain digitisation maturity, with three out of the four maturity dimensions, and the overall maturity construct $(p<.01)$.

The variable with the strongest correlation however, appears to be the employee size of the organisation. With all four dimensions as well as with the overall chain digitisation maturity measurement, this determinant shows a strong and significant correlation $(p<.01)$.

We conclude that complexity of chain digitisation solutions, synchronisation of data, and size of the organisation are the strongest determinants of the chain digitisation maturity of an organisation.

\section{CONCLUSION \& DISCUSSION}

In this paper, we developed a framework for chain digitisation maturity and turned this into a survey, which we applied on 33 (CIOs of) Dutch organisations. Next to defining and operationalising these main dimensions of chain digitisation maturity, the goal was to find and test the main determinants of this construct.

Our results indicate that the determinants of chain digitisation maturity are of a situational nature. Specifically: (i) non-standardised and complex chain digitisation solutions hinder maturity (H4), (ii) in situations where continuous synchronisation of data is of critical importance, chain digitisation maturity is higher (H5), and (iii) large organisations are more mature compared to smaller organisations (H6). Based on our current data, 'communication and collaboration' (H1) and the level of 'interorganisational trust' (H2) are not clearly related to the chain digitisation maturity level of an organisation. The determinant 'autonomy' (H3) was found to be negatively related to chain digitisation maturity, but only for the organisational dimension.

The situational nature of chain digitisation maturity is further underscored by the outcome from the clustering procedures. There we found a distinction between low scoring organisations on the one hand and medium/high scoring organisations on the other. This may point to the need for separate policies or approaches for these two types of organisations/ value chains. In terms of these policies, our model - and the specific operationalisation of it in our questionnaire - may prove useful for CIOs. It can help them in identifying the steps they could take in order to achieve the next maturity level. Furthermore, it also underscores the importance of paying attention to both the technological and the organisational dimension in improving an organisation's chain digitisation maturity. 
Plomp, M.G.A., Batenburg, R.S., Rooij, R.C.M. van. Determining chain digitisation maturity: a survey among Dutch CIOs. Electronic Markets: 2012, 22(4), 283-293

\section{[TABLE 7].}

When viewed from a strategic outside-in standpoint, our results seem to indicate that chain digitisation maturity is determined by 'unchangeable' factors of a specific chain constellation. When we take an inside-out perspective however, it can be concluded that every chain eventually achieves 'the maturity it needs'; i.e. the situational factors determine the right degree of chain digitisation. From the current state of several chains we believe that this cannot be fully true, as there are chains in which interorganisational IS/IT can still be significantly improved. We therefore propose that there must be other, more changeable factors, which influence chain digitisation too. Finding these remains one of our future research objectives. A major limitation of many studies on IOS, including this one, is that although the relevant information systems span multiple organisations (i.e. an entire value chain), often a single organisation is taken as the unit of analysis (cf. Reimers et al. 2010). Here, we tried to (partly) accommodate for this problem by explicitly defining the dependent variables on two sides of the organisation. This way, collaboration with different parties on two sides of the organisation is measured, thereby forming a proxy for assessment of three different organisational levels in the value chain (e.g. supplier, focal organisation and buyer). Clearly, in terms of validity it would have been stronger to pose the same questions to organisations up- and downstream the value chain.

Another way of measuring chain digitisation maturity at the chain level is by querying individual organisations of which it may be expected that they have an overview of the interorganisational field. An example is collecting data at the level of trade organisations (Plomp and Batenburg 2010). One could also approach this topic in a more qualitative way, through case studies of an entire value chain (e.g. Alt and Smits 2007; Grijpink et al. 2010). We hope to apply these and other innovative methods that deal with the issue of analysing an entire value chain in a cost-effective manner in our future research endeavours.

This study provides several other starting points for further study as well. Most prominently is the concept of (business/IT-) alignment (Chan and Reich 2007). With the addition of the distinction between the supply and demand sides of an organisation, the interrelation between these concepts becomes more interesting, but also more complex.

Future work on this or a similar, preferably larger dataset could shed light on this issue and build upon the 'arcs of integration' concept of Frohlich and Westbrook (2001).

Another topic is the special requirements for chain digitisation in the public domain (e.g. Grijpink 1999). With only 8 cases from this area in our current sample, we did not specifically look into those and considered all cases to be equal. However, in future research it would be interesting to focus specifically on non-profit organisations and determine whether the same and/or other factors come to surface. This fits well with the rising interest in services science (e.g.

Chesbrough and Spohrer 2006), as organisations in the public domain generally provide services, not products. A final recommendation for further assessing the 'situationality' of our model, would be to analyse the specific product/ service. For instance, it could be that services with high volume and low value are most likely to be supported electronically. By taking these and other characteristics into account, theory on interorganisational information systems can be extended and improved. 
Plomp, M.G.A., Batenburg, R.S., Rooij, R.C.M. van. Determining chain digitisation maturity: a survey among Dutch CIOs. Electronic Markets: 2012, 22(4), 283-293

\section{REFERENCES}

Alt, R., \& Smits, M. (2007). Networkability of organizations and business networks. Paper presented at the 15th European Conference on Information Systems.

Barney, J. (1991). Firm resources and sustained competitive advantage.

Journal of Management, 17(1), 99-120.

Barrett, S., \& Konsynski, B. (1982). Inter-organization information sharing systems. MIS Quarterly, 6, 93-105.

Batenburg, R. S., \& Versendaal, J. (2007). Business/IT-alignment for customer relationship management: framework and case studies.

International Journal of Electronic Customer Relationship Management, 1(3), 258-268.

Batenburg, R. S., \& Constantiou, I. D. (2009). A European study of ebusiness maturity and ICT-benefits: is there a conditional relationship? Paper presented at the 16th European Conference on Information Systems, Verona, Italy.

Bunker, D., Kautz, K., \& Pyne, C. (2008). Interorganizational systems adoption: a sociotechnical perspective. In G. León, A. Bernardos, J.

Casar, K. Kautz, \& J. DeGross (Eds.), Open IT-Based Innovation: Moving Towards Cooperative IT Transfer and Knowledge Diffusion (Vol. 287, IFIP International Federation for Information Processing) (pp. 159-175). Boston: Springer.

Chan, Y. E., \& Reich, B. H. (2007). IT alignment: an annotated bibliography. Journal of Information Technology, 22, 316- 396.

Chesbrough, H., \& Spohrer, J. (2006). A research manifesto for services science. Communications of the ACM, 49(7), 35-40.

Daft, R. L. (2001). Organizational theory and design (7th ed.).

Cincinnati: South-Western Educational Publishing.

Den Hertog, P. (2010). Managing service innovation: firm-level dynamic capabilities and policy options. Doctoral dissertation.

University of Amsterdam.

Frohlich, M. T., \& Westbrook, R. (2001). Arcs of integration: an international study of supply chain strategies. Journal of Operations Management, 19, 185-200.

Geri, N., \& Ahituv, N. (2008). A theory of constraints approach to interorganizational systems implementation. Information Systems and E-Business Management, 6(4), 341-360.

Grijpink, J. H. A. M. (1999). Chain-computerisation for interorganisational public policy implementation: a new approach to developing non-intrusive information infrastructures. Information Infrastructure and Policy, 6(2), 81-93.

Grijpink, J. H. A. M. (2010). Chain analysis for large-scale communication systems: a methodology for information exchange in chains. Journal of Chain-computerisation, 1, 132.

Grijpink, J. H. A. M., Visser, T., Dijkman, J. J., \& Plomp, M. G. A.

(2010). Towards an information strategy for the manic-depressive disorder chain-of-care. Journal of Chain-computerisation, 1, 1-11.

Håkansson, H., \& Ford, D. (2002). How should companies interact in business networks? Journal of Business Research, 55(2), 133-139.

Henderson, J. C., \& Venkatraman, N. (1993). Strategic alignment: leveraging information technology for transforming organizations.

IBM Systems Journal, 32(1), 4-16.

Kachigan, S. (1991). Multivariable statistical analysis. A conceptual introduction (2nd ed.). New York: Radius Press.

Kalakota, R., \& Robinson, M. (2001). E-business 2.0: roadmap for success. Boston: Addison-Wesley Longman.

Luftman, J., \& Kempaiah, R. (2007). An update on business-IT alignment: "A line" has been drawn. MIS Quarterly Executive, 6(3), 165-177.

Lunsford, T. K., \& Lunsford, B. R. (1995). The research sample, part I: sampling. Journal of Prosthetics and Orthotics, 7(3), 105-112.

Morrell, M., \& Ezingeard, J.-N. (2002). Revisiting adoption factors of inter-organisational information systems in SMEs. Logistics Information Management, 15(1), 46-57. 
Plomp, M.G.A., Batenburg, R.S., Rooij, R.C.M. van. Determining chain digitisation maturity: a survey among Dutch CIOs. Electronic Markets: 2012, 22(4), 283-293

Mumford, E. (1987). Sociotechnical systems design: evolving theory and practice. In G. Bjerknes, P. Ehn, \& M. Kyng (Eds.), Computers and democracy (pp. 59-76). Aldershot: Avebury.

Munkvold, B. E. (2005). Experiences from global e-collaboration: contextual influences on technology adoption and use. IEEE Transactions on Dependable and Secure Computing, 2(1), 78-86.

Nunnally, J. C., \& Bernstein, I. H. (1994). Psychometric theory (3rd ed.). New York: McGrawHill.

Orlikowski, W. J. (1992). The duality of technology: rethinking the concept of technology in organizations. Organization Science, 3 (3), 398-427.

Plomp, M. G. A., \& Batenburg, R. S. (2009). Procurement maturity, alignment and performance: a Dutch hospital case comparison.

Paper presented at the 22nd Bled eConference "eEnablement: Facilitating an Open, Effective and Representative eSociety", Bled, Slovenia.

Plomp, M. G. A., \& Batenburg, R. S. (2010). Measuring chain digitisation maturity: an assessment of Dutch retail branches. Supply Chain Management: An International Journal, 15(3), 227-237.

Reimers, K., Johnston, R. B., \& Klein, S. (2010). The difficulty of studying inter-organisational IS phenomena on large scales: critical reflections on a research journey. Electronic Markets, 20(3- 4), 229-240.

Robey, D., Im, G., \& Wareham, J. D. (2008). Theoretical foundations of empirical research on interorganizational systems: assessing past contributions and guiding future directions. Journal of the Association for Information Systems, 9(9), 497-518.

Scott Morton, M.S. (Ed.). (1991). The corporation of the 1990s: Information technology and organizational transformation.

Oxford University Press.

Teece, D. J. (2007). Explicating dynamic capabilities: the nature and microfoundations of (sustainable) enterprise performance.

Strategic Management Journal, 28(13), 1319-1350.

Teece, D., Pisano, G., \& Shuen, A. (1997). Dynamic capabilities and strategic management. Strategic Management Journal, 18(7), 509-533.

Teo, T. S. H., Lin, S., \& Lai, K. H. (2009). Adopters and non-adopters of e-procurement in Singapore: an empirical study. Omega, 37(5), 972-987.

Turban, E., McLean, E. R., \& Wetherbe, J. C. (2001). Information technology for management: making connections for strategic advantage (2nd ed.). New York: Wiley.

Turban, E., King, D., Viehland, D., \& Lee, J. K. (2004). Electronic commerce 2004: a managerial perspective. Upper Saddle River: Pearson-Prentice Hall.

Van Beers, C., \& Bouwman, H. (2007). Travel agents and ICT technologies.

In T. Wolters (Ed.), Measuring the new economy: statistics between hard-boiled indicators and intangible phenomena (pp. 127-142). Amsterdam: Elsevier.

Wernerfelt, B. (1984). A resource-based view of the firm. Strategic Management Journal, 5(2), 171-180.

Zhu, K., \& Kraemer, K. L. (2002). E-commerce metrics for netenhanced organizations: assessing the value of e-commerce to firm performance in the manufacturing sector. Information Systems Research, 13(3), 275-295. 
Plomp, M.G.A., Batenburg, R.S., Rooij, R.C.M. van. Determining chain digitisation maturity: a survey among Dutch CIOs. Electronic Markets: 2012, 22(4), 283-293

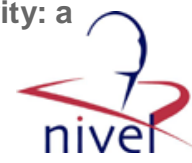

\section{TABLES AND FIGURES}

Fig. 1 Chain digitisation maturity levels for both the technological and organisational dimension (Plomp and Batenburg 2010)

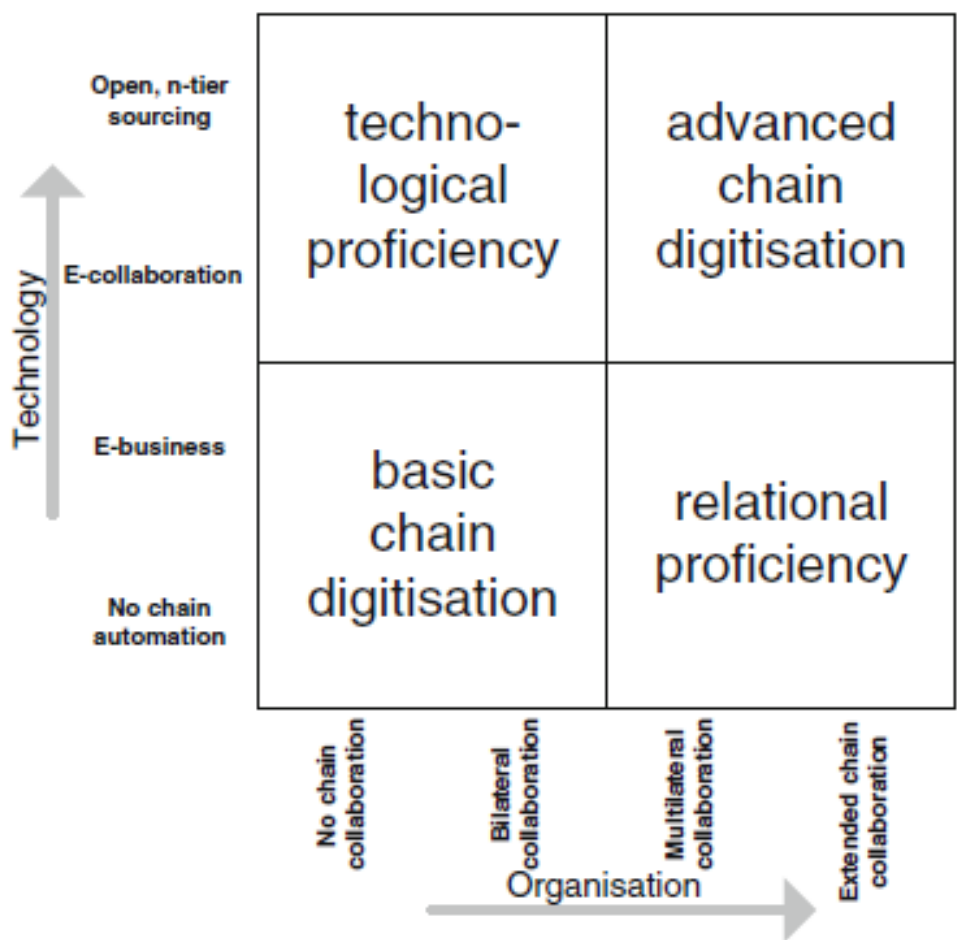

Fig. 2 The conceptual model

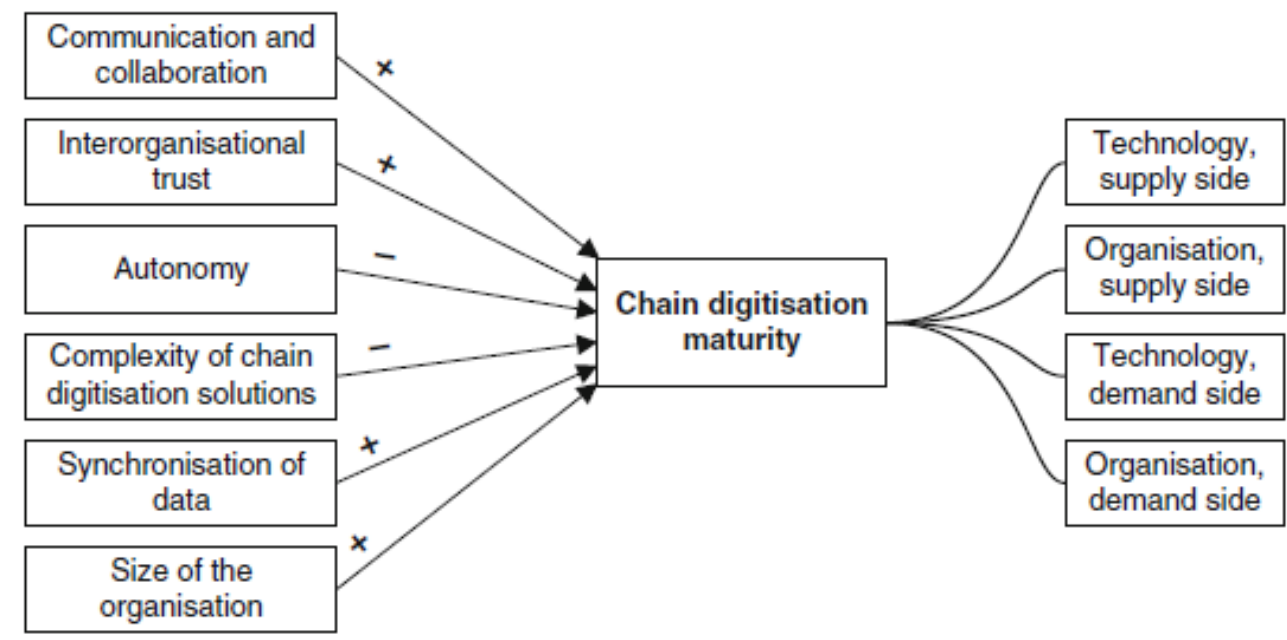


Table 1 Determinants and the survey questions employed to measure them

\begin{tabular}{|c|c|}
\hline Determinant & Question used for measuring the determinant \\
\hline Communication and collaboration & $\begin{array}{l}\text { With regard to interorganisational communication, our organisation is strongly limited by our } \\
\text { existing/legacy systems. }\end{array}$ \\
\hline Interorganisational trust & There is a high level of trust between the parties within our value chain. \\
\hline Autonomy & $\begin{array}{l}\text { There are one or a few dominant players in our value chain who decide all organisational } \\
\text { issues on collaboration and agreements. }\end{array}$ \\
\hline Synchronisation of data & $\begin{array}{l}\text { Continuous synchronisation of data }(24 \times 7 \text {, real time) with our value chain partners is of great } \\
\text { importance to our organisation. }\end{array}$ \\
\hline Size of the organisation & What is currently the total head-count of your organisation in terms of persons? \\
\hline
\end{tabular}


Plomp, M.G.A., Batenburg, R.S., Rooij, R.C.M. van. Determining chain digitisation maturity: a survey among Dutch CIOs. Electronic Markets: 2012, 22(4), 283-293

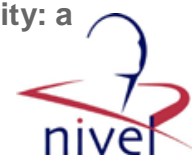

Table 2 Maturity dimensions and the survey questions employed to measure them

\begin{tabular}{|c|c|}
\hline Maturity dimension & Questions used for measuring the maturity dimension \\
\hline Technology, supply side & $\begin{array}{l}\text { To support the purchase function, does your organisation use specific IT systems/applications for: } \\
\text { - Ordering goods or services online? } \\
\text { - Arranging payments online for ordered products or services? } \\
\text { - Receiving e-invoices? } \\
\text { - Finding suppliers in the market? } \\
\text { - Inviting suppliers to quote prices or submit proposals? } \\
\text { - Running online auctions? } \\
\text { - Collaborating with suppliers to forecast your demand? } \\
\text { - Collaborating with suppliers to design new products or services? } \\
\text { - Managing capacity or inventories of suppliers? }\end{array}$ \\
\hline Organisation, supply side & $\begin{array}{l}\text { To support the purchase function, does your organisation apply specific (i.e. customised and written) } \\
\text { organisational arrangements to: } \\
\text { - Document delivery contracts on the operational level? } \\
\text { - Settle strategic alliances? } \\
\text { - Share strategic information? } \\
\text { - Evaluate supplier performance on contract parameters? } \\
\text { - Document joint process descriptions with suppliers? } \\
\text { - Govern a joint work team with suppliers? } \\
\text { - Align your strategy with your suppliers' strategy? }\end{array}$ \\
\hline Technology, demand side & $\begin{array}{l}\text { To support the sales function, does your organisation use specific IT systems/applications for: } \\
\text { - Receiving online orders? } \\
\text { - Enabling payments online for ordered products or services? } \\
\text { - Sending e-invoices? } \\
\text { - Sending offers? } \\
\text { - Answering calls after proposals or tenders? } \\
\text { - Launching sales auctions, for example on B2B or B2C marketplaces? } \\
\text { - Collaborating with customers to forecast their demand? } \\
\text { - Collaborating with customers to design new products or services? } \\
\text { - Managing capacity or inventories of customers? }\end{array}$ \\
\hline Organisation, demand side & $\begin{array}{l}\text { To support the sales function, does your organisation apply specific (i.e. customised and written) } \\
\text { organisational arrangements to: } \\
\text { - Document delivery contracts on the operational level? } \\
\text { - Settle strategic alliances with your customers? } \\
\text { - Share strategic information with customers? } \\
\text { - Evaluate your performance on contract parameters? } \\
\text { - Document joint process descriptions with customers? } \\
\text { - Govern a joint work team with your customers? } \\
\text { - Align your strategy with your customers' strategy? }\end{array}$ \\
\hline
\end{tabular}


Plomp, M.G.A., Batenburg, R.S., Rooij, R.C.M. van. Determining chain digitisation maturity: a survey among Dutch CIOs. Electronic Markets: 2012, 22(4), 283-293

Table 3 Sector distribution of sample $(n=33)$

\begin{tabular}{|c|c|c|}
\hline Sector & $n$ & $\%$ \\
\hline Construction & 2 & $6.1 \%$ \\
\hline Education & 4 & $12.1 \%$ \\
\hline Government & 1 & $3.0 \%$ \\
\hline Healthcare & 2 & $6.1 \%$ \\
\hline Logistics & 3 & $9.1 \%$ \\
\hline $\begin{array}{l}\text { Manufacturing/ } \\
\text { producing }\end{array}$ & 9 & $27.3 \%$ \\
\hline Professional services & 9 & $27.3 \%$ \\
\hline Retail/wholesale & 3 & $9.1 \%$ \\
\hline
\end{tabular}

Table 4 Area of operation and organisational age of sample $(n=33)$

\begin{tabular}{lrllrl}
\hline Area of operation & $n$ & $\%$ & $\begin{array}{l}\text { Age of } \\
\text { organisation }\end{array}$ & $n$ & $\%$ \\
\hline $\begin{array}{l}\text { Local/regional } \\
\begin{array}{l}\text { National (i.e. the } \\
\text { Netherlands) }\end{array}\end{array}$ & 42 & $36.4 \%$ & $10-50$ years & 18 & $54.5 \%$ \\
$\begin{array}{l}\text { Continental } \\
\text { (i.e. Europe) }\end{array}$ & 10 & $30.3 \%$ & $51-100$ years & 7 & $21.2 \%$ \\
\begin{tabular}{l} 
Global \\
\hline
\end{tabular} & 7 & $21.2 \%$ & $>100$ years & 4 & $12.1 \%$ \\
\hline
\end{tabular}


Table 5 Descriptive statistics of the chain digitisation maturity dimensions (dependent variables; $n=33$ )

\begin{tabular}{lcccc}
\hline Variable & Mean & SD & Min. & Max. \\
\hline Technology, supply side & 1.89 & 0.72 & 1 & 4 \\
Organisation, supply side & 2.09 & 1.06 & 1 & 4 \\
Technology, demand side & 2.04 & 0.84 & 1 & 4 \\
Organisation, demand side & 2.33 & 1.07 & 1 & 4 \\
Overall chain digitisation maturity & 2.07 & 0.79 & 1 & 4 \\
\hline
\end{tabular}

Fig. 3 Clustering of cases for supply side chain digitisation maturity

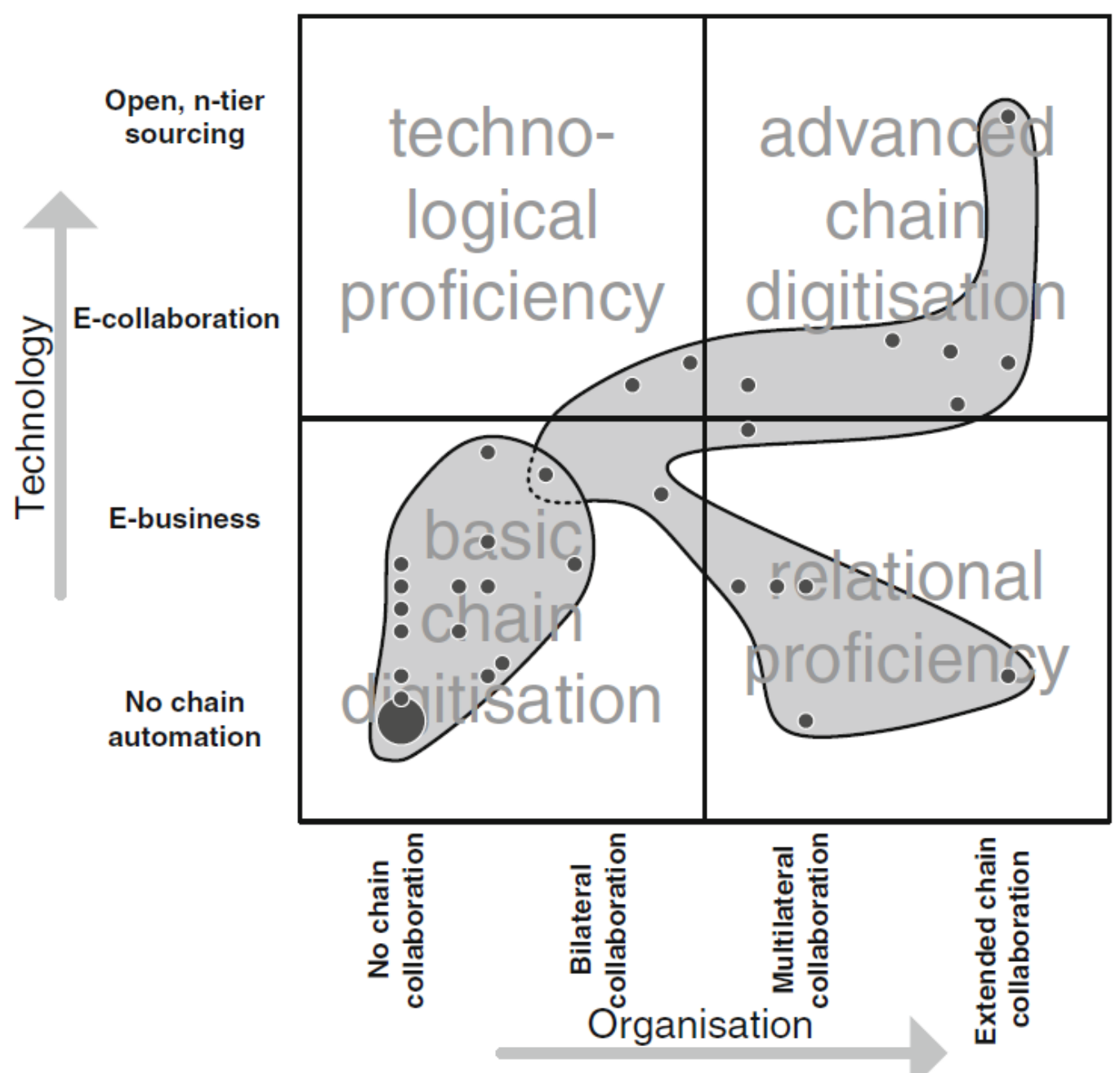


Plomp, M.G.A., Batenburg, R.S., Rooij, R.C.M. van. Determining chain digitisation maturity: a survey among Dutch CIOs. Electronic Markets: 2012, 22(4), 283-293

Fig. 4 Clustering of cases for demand side chain digitisation maturity

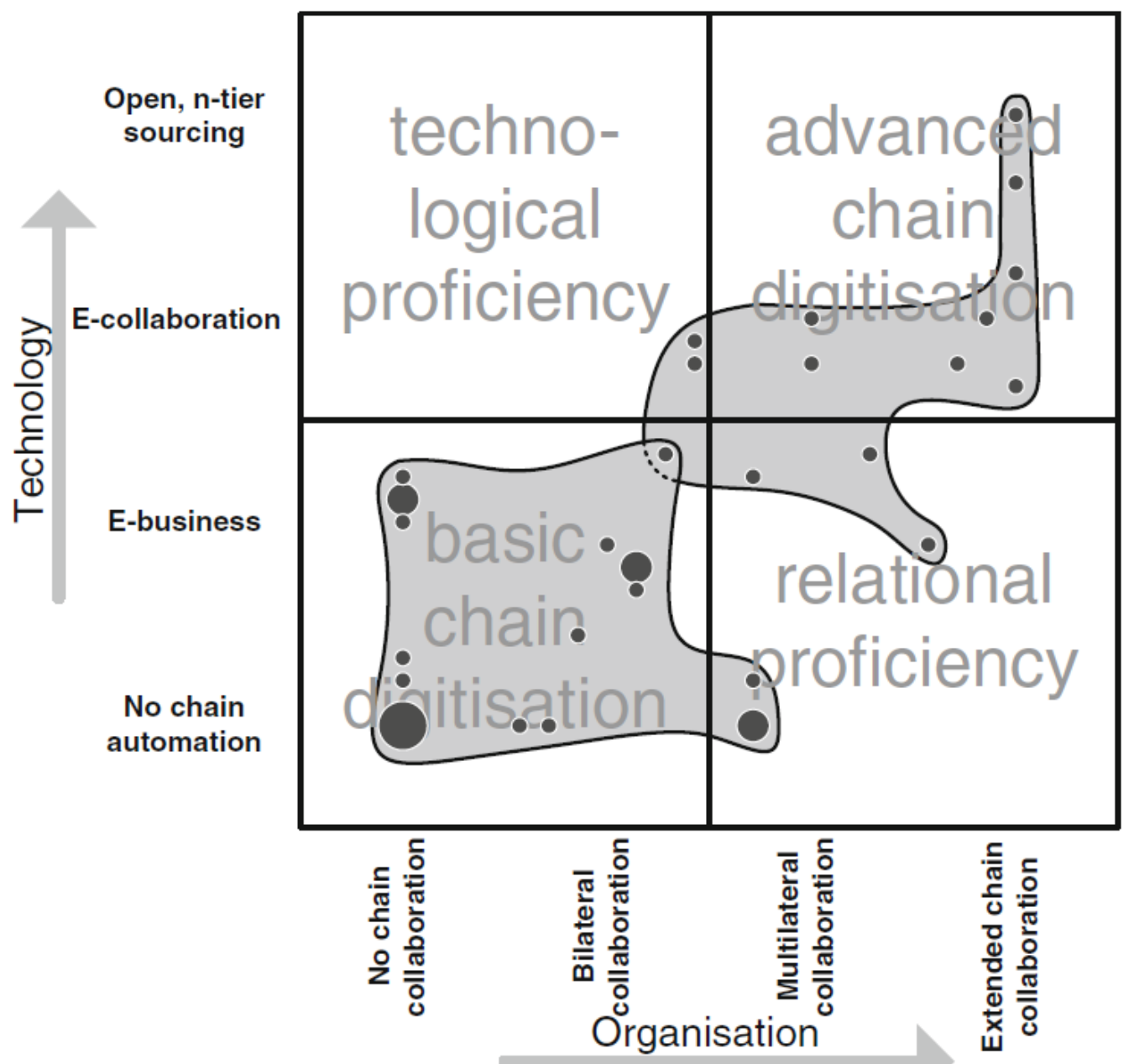


Plomp, M.G.A., Batenburg, R.S., Rooij, R.C.M. van. Determining chain digitisation maturity: a survey among Dutch CIOs. Electronic Markets: 2012, 22(4), 283-293

Table 6 Descriptive statistics of the chain digitisation maturity determinants (independent variables; $n=33$ )

Variable Mean SD Min. Max.

Communication and collaboration

$\begin{array}{llll}4.48 & 1.58 & 2 & 7\end{array}$

Interorganisational trust

$\begin{array}{llll}4.36 & 1.22 & 2 & 6\end{array}$

Autonomy

$\begin{array}{llll}4.64 & 1.45 & 1 & 7\end{array}$

Complexity of chain digitisation solutions

$\begin{array}{llll}4.64 & 1.69 & 1 & 7\end{array}$

Synchronisation of data

$\begin{array}{llll}4.09 & 2.28 & 1 & 7\end{array}$

Size of the organisation (logarithm)

$\begin{array}{llll}2.77 & 1.32 & 1.08 & 5.08\end{array}$


Table 7 Pearson correlations between chain digitisation maturity and its determinants (1-tailed; $n-33) ;{ }^{*}$ significant correlation at the .05 level; **=significant correlation at the .01 level

\begin{tabular}{|c|c|c|c|c|c|c|c|c|c|c|}
\hline \multirow[t]{2}{*}{ Determinant } & \multicolumn{2}{|c|}{$\begin{array}{l}\text { Technology, } \\
\text { supply side }\end{array}$} & \multicolumn{2}{|c|}{$\begin{array}{l}\text { Organisation, } \\
\text { supply side }\end{array}$} & \multicolumn{2}{|c|}{$\begin{array}{l}\text { Technology, } \\
\text { demand side }\end{array}$} & \multicolumn{2}{|c|}{$\begin{array}{l}\text { Organisation, } \\
\text { demand side }\end{array}$} & \multicolumn{2}{|c|}{$\begin{array}{l}\text { Overall chain } \\
\text { digitisation maturity }\end{array}$} \\
\hline & $\mathrm{r}$ & $\mathrm{p}$ & $\mathrm{r}$ & $\mathrm{p}$ & $\mathrm{r}$ & $\mathrm{p}$ & $\mathrm{r}$ & $\mathrm{p}$ & $\mathrm{r}$ & $\mathrm{p}$ \\
\hline Communication and collaboration & -0.06 & 0.38 & -0.18 & 0.16 & -0.01 & 0.48 & -0.10 & 0.28 & -0.10 & 0.29 \\
\hline Interorganisational trust & -0.02 & 0.46 & -0.19 & 0.15 & -0.05 & 0.40 & -0.13 & 0.24 & -0.11 & 0.28 \\
\hline Synchronisation of data & $0.44 * *$ & 0.01 & 0.26 & 0.07 & $0.59 * *$ & 0.00 & $0.31^{*}$ & 0.04 & $0.46^{* *}$ & 0.00 \\
\hline Size of the organisation (logarithm) & $0.63 * *$ & 0.00 & $0.53 * *$ & 0.00 & $0.44 * *$ & 0.01 & $0.43^{* *}$ & 0.01 & $0.57 * *$ & 0.00 \\
\hline
\end{tabular}

